\title{
High vascular endothelial growth factor gene expression predicts poor outcome in patients with non-luminal A breast cancer
}

\author{
DOONYAPAT SA-NGUANRAKSA ${ }^{1}$, TUENJAI CHUANGSUWANICH ${ }^{2}$, \\ TAWATCHAI PONGPRUTTIPAN ${ }^{2}$ and PORNCHAI O-CHAROENRAT ${ }^{1}$ \\ ${ }^{1}$ Division of Head, Neck and Breast Surgery, Department of Surgery and ${ }^{2}$ Department of Pathology, \\ Faculty of Medicine, Siriraj Hospital, Mahidol University, Bangkok 10700, Thailand
}

Received December 23, 2014; Accepted March 4, 2015

DOI: $10.3892 / \operatorname{mco} .2015 .574$

\begin{abstract}
Breast cancer is the most frequent type of cancer among women worldwide. Vascular endothelial growth factor (VEGF), the key modulator of angiogenesis, has been implicated in breast cancer susceptibility and aggressiveness. VEGF expression was determined in 99 breast cancer tissue samples using reverse transcription-polymerase chain reaction and the human epidermal growth factor receptor 2 (HER2) status was determined by immunohistochemistry. Subsequently, the associations of VEGF, HER2 and hormone receptor status with clinicopathological data were evaluated. High VEGF expression was found to be significantly correlated with the presence of lymphovascular invasion. In hormone receptor-positive/HER2-positive, HER2-positive and triple-negative breast cancer, high $V E G F$ expression was correlated with the presence of axillary nodal metastasis and lower overall survival rates. Therefore, the assessment of the $V E G F$ status along with the hormone receptor and HER2 status may help identify high-risk patients who may benefit from anti-VEGF treatment.
\end{abstract}

\section{Introduction}

Breast cancer is the most frequent type of cancer among women worldwide, with increasing incidence rates in the majority of countries (1). In Thailand, breast cancer is also the most common type of cancer among women (2). Genetic alteration is one of the key factors involved in breast cancer initiation and progression. Human epidermal growth factor receptor 2 (HER2), an onco-

Correspondence to: Professor Pornchai O-Charoenrat, Division of Head, Neck and Breast Surgery, Department of Surgery, Faculty of Medicine, Siriraj Hospital, Mahidol University, 2 Wanglang Road, Bangkoknoi, Bangkok 10700, Thailand

E-mail: pornchai.och@mahidol.ac.th

Key words: angiogenesis, breast cancer, growth factor, human epidermal growth factor receptor 2, hormone receptor, vascular endothelial growth factor gene that is amplified and overexpressed in breast cancer, has been correlated with more aggressive characteristics, including negative estrogen receptor (ER) and progesterone receptor (PR) status, higher histological grading, lymph node involvement and resistance to chemotherapy.

In addition to oncogene alterations, angiogenesis, the formation of new blood vessels, is of particular significance in the process of cancer growth, invasion and metastasis $(3,4)$. The most important key modulator in this complex process is vascular endothelial growth factor (VEGF). The expression of VEGF has been correlated with the presence of higher microvessel density (MVD), lymphovascular invasion (LVI) and shorter disease-free survival (DFS) and overall survival (OS).

The analysis of plasma VEGF levels in metastatic breast cancer patients receiving bevacizumab demonstrated that VEGF levels $>32.6 \mathrm{pg} / \mathrm{ml}$ were associated with shorter time-to-progression (5). The evaluation of VEGF in a randomized control trial on HER2-negative metastatic breast cancer revealed that the pretreatment plasma concentration of VEGF was correlated with a greater treatment effect. In addition, patients with higher VEGF concentrations exhibited lower hazard ratio (bevacizumab + docetaxel vs. placebo + docetaxel) (6). A study of $V E G F$ polymorphisms in advanced breast cancer patients who were treated with paclitaxel alone or paclitaxel+bevacizumab (Eastern Cooperative Oncology Group 2100) revealed that VEGF-2578 AA and -1154 AA were associated with better OS in the combination arm (7).

HER2 activation is one of several mechanisms that upregulate VEGF expression. The evaluation of $V E G F$ along with HER2, ER and PR status may provide useful information regarding the aggressiveness of breast cancer and may help identify patients who are suitable for anti-VEGF treatment.

\section{Patients and methods}

Study population. The patients were recruited from the Division of Head-Neck and Breast Surgery, Department of Surgery, Faculty of Medicine, Siriraj Hospital (Bangkok, Thailand), between 2002 and 2004. All the patients with histopathologically confirmed breast carcinoma fulfilling the selection criteria were asked to be participated in this study. Patients who were diagnosed with breast cancer, aged $\geq 18$ years and able to provide written informed consent, were included in the 
study. Patients with history of other cancers were excluded. At recruitment, informed consent was obtained from all the subjects and each participant was interviewed to collect detailed information on demographic characteristics and family history of cancer.

This study's protocol was approved by the Institutional Review Board of the Siriraj Hospital.

Immunohistochemistry. The expression levels of HER2 and MVD in breast cancer tissue were assessed by immunohistochemical staining with specific antibodies. Paraffin-embedded sections from each specimen were stained with monoclonal rabbit antihuman HER2 antibody, clone 4B5 (ready to use, incubation time 8 h; catalog no. 790-289921; Roche Diagnostics GmbH, Mannheim, Germany) and monoclonal mouse anti-human antibody to transmembrane glycoprotein CD31, clone JC70A (dilution 1:300, incubation time 16 h; catalog no. M082301; Dako Denmark A/S, Glostrup, Denmark). The $3-\mu \mathrm{m}$ sections were incubated at $56^{\circ} \mathrm{C}$ overnight, deparaffinized and rehydrated. To block endogenous peroxidase activity, the sections were incubated in $3 \% \mathrm{H}_{2} \mathrm{O}_{2}$ in deionized water for $10 \mathrm{~min}$ and then washed with running distilled water for $5 \mathrm{~min}$. Antigen retrieval was performed by boiling the sections in $10 \mathrm{mmol} / \mathrm{l}$ citrate buffer ( $\mathrm{pH}$ 6.0). The sections were placed in phosphate-buffered saline (PBS) for $10 \mathrm{~min}$ and then in $2 \%$ bovine serum albumin (BSA) for $30 \mathrm{~min}$. The excess BSA was removed. The sections were stained with the primary antibody at room temperature, washed twice with PBS for 5 min, incubated with secondary rabbit anti-mouse antibody (catalog no. K500711; EnVision; Dako Denmark A/S) for $30 \mathrm{~min}$. Following incubation, the sections were washed twice with PBS for $5 \mathrm{~min}$, incubated in 3,3'-diaminobenzidine for $5 \mathrm{~min}$ and washed in tap water for $5 \mathrm{~min}$. The sections were counterstained with haematoxylin, dehydrated, fixed and mounted. All the immunohistochemical data were evaluated by two pathologists who were blinded to the patients' characteristics and clinical outcome.

Assessment of VEGF mRNA expression levels. The levels of $V E G F$ mRNA expression were assayed by semiquantitative reverse transcription-polymerase chain reaction, as previously described (8). Each RNA sample was assayed in duplicate and in two separate settings.

Statistical analysis. Patient data on cancer recurrence and death were retrieved through medical record review. The dates of recurrence and death were recorded. The date of last contact was defined as the date of the patient's last visit to the department where they had received breast cancer therapy (Division of Head-Neck and Breast Surgery, Department of Surgery; Division of Oncology, Department of Medicine; and Division of Therapeutic Radiology, Department of Radiology, Siriraj Hospital). The DFS analysis endpoint was cancer recurrence/metastasis or breast cancer-related death. DFS was defined as the time from diagnosis to the endpoint (recurrence, metastasis, or breast cancer-related death), censoring at the date of last contact or non-cancer death. The OS analysis endpoint was breast cancer-related death. OS was defined as the time from diagnosis to the endpoint of the study, censoring at the date of last contact or non-cancer death. Survival curves were constructed using the Kaplan-Meier product-limit method and statistical significance was assessed using the log-rank test. A multivariate analysis was performed to evaluate the effect of prognostic factors on OS, using the Cox proportional hazards model. The statistical analyses were conducted using SPSS software version 15.0 (IBM Corp., Armonk, NY, USA). P<0.05 was considered to indicate statistically significant differences.

\section{Results}

VEGF mRNA expression in breast cancer tissue. A total of 99 breast cancer patients were recruited. The patient characteristics are summarized in Table I. The mean age at diagnosis was 51.42 years (range, 39.49-63.35 years), with a median age of 50 years. A total of 91 patients had invasive ductal carcinoma; 62 patients had tumor size $>20-50 \mathrm{~mm}$; 55 patients had axillary nodal metastasis and 6 patients had distant metastasis at the time of diagnosis. The assessment of $V E G F$ mRNA expression revealed that the mRNA ratio ranged from 0 to 3.27 , with a median mRNA ratio of 1.16 . At this cut-off value, 49 patients exhibited low and 50 patients high VEGF mRNA expression.

Correlation between VEGF expression and clinicopathological characteristics. On univariate analysis, high VEGF expression was correlated with the presence of LVI [odds ratio $(\mathrm{OR})=2.96,95 \%$ confidence interval $(\mathrm{CI})$ : 1.28-6.83; $\mathrm{P}=0.011]$. High VEGF expression tended to be correlated with locally advanced breast cancer [stage III (except T3N1M0) and IV] $(\mathrm{OR}=2.30$, 95\% CI: 0.96-5.54; $\mathrm{P}=0.062)$. However, the multivariate analysis failed to demonstrate the statistical significance of this correlation. The distribution of VEGF expression status by different clinicopathological characteristics is summarized in Table II. Breast cancer patients were classified into 4 groups according to the ER, PR and HER2 status. The numbers of patients with hormone receptor-positive/HER2-negative, hormone receptor-positive/HER2-positive, HER2-positive and triple-negative breast cancer were 47 (47.47\%), 10 (10.10\%), $17(17.17 \%)$ and $25(25.25 \%)$, respectively.

In patients with hormone receptor-positive/HER2-positive, HER2-positive and triple-negative breast cancer, high VEGF expression was correlated with axillary nodal metastasis $(\mathrm{OR}=3.56,95 \%$ CI: 1.13-11.15; $\mathrm{P}=0.030)$. High VEGF expression was also correlated with the presence of LVI in patients with hormone receptor-positive/HER2-negative (OR=3.75, 95\% CI: 1.08-13.07; $\mathrm{P}=0.038$ ).

Survival analysis. The median follow-up was 58.73 months (range, 1.23-93.03 months). The univariate analysis of survival by the Kaplan-Meier method revealed that the presence of perineural invasion (PNI), PR negativity and the presence of axillary nodal metastasis were correlated with lower DFS rates $(\mathrm{P}<0.001, \mathrm{P}=0.017$ and 0.043 , respectively). The presence of PNI, PR negativity, the presence of distant metastasis at the time of diagnosis and advanced-stage breast cancer were correlated with lower OS ( $\mathrm{P}=0.011,0.035,0.003$ and 0.009 , respectively). The DFS and OS rates by clinicopathological characteristics and levels of VEGF expression are summarized in Table III. In the hormone receptor-positive/HER2-positive, HER2-positive and triple-negative groups, the presence of PNI was associated 
Table I. Clinicopathological and demographic characteristics of breast cancer patients.

\begin{tabular}{|c|c|}
\hline Characteristics & $\begin{array}{c}\text { Patients, no. }(\%) \\
(\mathrm{n}=99)\end{array}$ \\
\hline \multicolumn{2}{|l|}{ Age at diagnosis, years } \\
\hline$<50$ & $49(49.50)$ \\
\hline$\geq 50$ & $50(50.50)$ \\
\hline \multicolumn{2}{|l|}{ Tumor type } \\
\hline Invasive ductal carcinoma & $91(91.92)$ \\
\hline Invasive lobular carcinoma & $3(3.03)$ \\
\hline Others & $5(5.05)$ \\
\hline \multicolumn{2}{|l|}{ Tumor size, mm } \\
\hline$\leq 20$ & $20(20.20)$ \\
\hline $20-50$ & $62(62.63)$ \\
\hline$>50$ & $17(17.17)$ \\
\hline \multicolumn{2}{|l|}{ Axillary nodal metastasis } \\
\hline No & $44(44.44)$ \\
\hline Yes & $55(55.56)$ \\
\hline \multicolumn{2}{|l|}{ Distant metastasis } \\
\hline No & 93 (93.94) \\
\hline Yes & $6(6.06)$ \\
\hline \multicolumn{2}{|l|}{ Stage at diagnosis } \\
\hline $\mathrm{I}$ & $12(12.12)$ \\
\hline II & $52(52.53)$ \\
\hline III & $29(29.29)$ \\
\hline IV & $6(6.06)$ \\
\hline \multicolumn{2}{|l|}{ Histological differentiation } \\
\hline High & $3(3.03)$ \\
\hline Moderate & $58(58.59)$ \\
\hline Poor & $35(35.35)$ \\
\hline Unknown & $3(3.03)$ \\
\hline \multicolumn{2}{|l|}{ Lymphovascular invasion } \\
\hline Absent & 49 (49.49) \\
\hline Present & $46(46.46)$ \\
\hline \multicolumn{2}{|l|}{ Perineural invasion } \\
\hline Absent & 73 (73.74) \\
\hline Present & $15(15.15)$ \\
\hline \multicolumn{2}{|l|}{ Estrogen receptor } \\
\hline Negative & $42(42.42)$ \\
\hline Positive & $57(57.58)$ \\
\hline \multicolumn{2}{|l|}{ Progesterone receptor } \\
\hline Negative & $57(57.58)$ \\
\hline Positive & $42(42.42)$ \\
\hline \multicolumn{2}{|l|}{ HER 2} \\
\hline Negative & $72(72.73)$ \\
\hline Positive & $27(27.27)$ \\
\hline
\end{tabular}

Data for lymphovascular and perineural invasion could not be pathologically confirmed for all the patients. HER2, human epidermal growth factor receptor 2 .

with lower DFS rates $(\mathrm{P}<0.001)$. High VEGF expression, the presence of distant metastasis at the time of diagnosis and
Table II. Proportion of VEGF expression among different clinicopathological characteristics.

\begin{tabular}{|c|c|c|c|}
\hline \multirow[b]{2}{*}{ Characteristics } & \multicolumn{2}{|c|}{ mRNA expression } & \multirow[b]{2}{*}{ P-value } \\
\hline & $\begin{array}{c}\text { Low } \\
(n=49)\end{array}$ & $\begin{array}{l}\text { High } \\
(n=50)\end{array}$ & \\
\hline Age, years & & & 0.482 \\
\hline$<50$ & 26 & 23 & \\
\hline$\geq 50$ & 23 & 27 & \\
\hline Tumor size, mm & & & 0.121 \\
\hline$\leq 20$ & 13 & 7 & \\
\hline$>20$ & 36 & 43 & \\
\hline Axillary nodal metastasis & & & 0.088 \\
\hline No & 26 & 18 & \\
\hline Yes & 23 & 32 & \\
\hline Distant metastasis & & & 0.097 \\
\hline No & 48 & 45 & \\
\hline Yes & 1 & 5 & \\
\hline Early-stage cancer & & & 0.060 \\
\hline Yes & 38 & 30 & \\
\hline No & 11 & 20 & \\
\hline Histological differentiation & & & 0.806 \\
\hline High & 2 & 1 & \\
\hline Moderate & 28 & 30 & \\
\hline Poor & 18 & 17 & \\
\hline Lymphovascular invasion & & & 0.010 \\
\hline Absent & 30 & 19 & \\
\hline Present & 16 & 30 & \\
\hline Perineural invasion & & & 0.451 \\
\hline Absent & 37 & 36 & \\
\hline Present & 6 & 9 & \\
\hline Estrogen receptor & & & 0.257 \\
\hline Positive & 31 & 26 & \\
\hline Negative & 18 & 24 & \\
\hline Progesterone receptor & & & 0.191 \\
\hline Positive & 24 & 18 & \\
\hline Negative & 25 & 32 & \\
\hline Hormone receptor & & & 0.257 \\
\hline Positive & 31 & 26 & \\
\hline Negative & 18 & 24 & \\
\hline HER2 & & & 0.101 \\
\hline Negative & 32 & 40 & \\
\hline Positive & 17 & 10 & \\
\hline
\end{tabular}

HER2, human epidermal growth factor receptor 2.

advanced-stage breast cancer were found to be correlated with lower OS rates $(\mathrm{P}=0.041,<0.001$ and 0.008 , respectively; data not shown). In the hormone receptor-positive/HER2-negative group, the presence of PNI and distant metastasis at the time of diagnosis were correlated with lower OS rates $(\mathrm{P}=0.019$ and 0.013 , respectively; data not shown). However, the Cox 
Table III. Disease-free survival (DFS) and overall survival (OS) by clinicopathological characteristics and VEGF expression level.

\begin{tabular}{|c|c|c|c|c|c|c|c|c|}
\hline \multirow[b]{2}{*}{ Characteristics } & \multicolumn{4}{|c|}{ DFS } & \multicolumn{4}{|c|}{ OS } \\
\hline & $\begin{array}{c}\text { Cases } \\
(\mathrm{n}=90)\end{array}$ & $\begin{array}{l}\text { Events } \\
(n=20)\end{array}$ & $\begin{array}{c}\text { 5-year survival } \\
(\%)\end{array}$ & P-value & $\begin{array}{l}\text { Cases } \\
(n=96)\end{array}$ & $\begin{array}{l}\text { Events } \\
(n=9)\end{array}$ & $\begin{array}{c}\text { 5-year survival } \\
(\%)\end{array}$ & P-value \\
\hline Age, years & & & & 0.679 & & & & 0.719 \\
\hline$<50$ & 45 & 9 & 80.0 & & 47 & 4 & 91.5 & \\
\hline$\geq 50$ & 45 & 11 & 75.6 & & 49 & 5 & 89.8 & \\
\hline Tumor size, mm & & & & 0.059 & & & & 0.117 \\
\hline$\leq 20$ & 28 & 1 & 94.4 & & 19 & 0 & 100.0 & \\
\hline$>20$ & 72 & 19 & 73.6 & & 77 & 9 & 88.3 & \\
\hline $\begin{array}{l}\text { Histological } \\
\text { differentiation }\end{array}$ & & & & 0.449 & & & & 0.862 \\
\hline High/moderate & 55 & 13 & 76.4 & & 60 & 5 & 91.7 & \\
\hline Poor & 33 & 6 & 81.8 & & 33 & 3 & 90.9 & \\
\hline LVI & & & & 0.354 & & & & 0.314 \\
\hline Absent & 46 & 8 & 82.6 & & 49 & 3 & 93.9 & \\
\hline Present & 40 & 10 & 75.0 & & 43 & 5 & 88.4 & \\
\hline PNI & & & & $<0.001$ & & & & 0.011 \\
\hline Absent & 67 & 9 & 86.6 & & 72 & 3 & 95.8 & \\
\hline Present & 13 & 7 & 46.2 & & 14 & 3 & 78.6 & \\
\hline ER & & & & 0.822 & & & & 0.141 \\
\hline Positive & 52 & 11 & 78.8 & & 56 & 3 & 94.6 & \\
\hline Negative & 38 & 9 & 76.3 & & 40 & 6 & 85.0 & \\
\hline PR & & & & 0.017 & & & & 0.035 \\
\hline Positive & 38 & 4 & 89.5 & & 41 & 1 & 97.6 & \\
\hline Negative & 52 & 16 & 69.2 & & 55 & 8 & 85.5 & \\
\hline Hormone receptor & & & & 0.822 & & & & 0.141 \\
\hline Positive & 52 & 11 & 78.8 & & 56 & 3 & 94.6 & \\
\hline Negative & 38 & 9 & 76.3 & & 40 & 6 & 85.0 & \\
\hline HER 2 & & & & 0.457 & & & & 0.245 \\
\hline Negative & 64 & 13 & 79.7 & & 70 & 5 & 92.9 & \\
\hline Positive & 26 & 7 & 73.1 & & 26 & 4 & 84.6 & \\
\hline Subtype & & & & 0.813 & & & & 0.110 \\
\hline HR+HER2- & 42 & 9 & 78.6 & & 46 & 2 & 95.7 & \\
\hline Others & 48 & 11 & 77.1 & & 50 & 7 & 86.0 & \\
\hline$V E G F$ & & & & 0.745 & & & & 0.076 \\
\hline Low & 47 & 10 & 78.7 & & 48 & 2 & 95.8 & \\
\hline High & 43 & 10 & 76.7 & & 48 & 7 & 85.4 & \\
\hline $\begin{array}{l}\text { Axillary nodal } \\
\text { metastasis }\end{array}$ & & & & 0.043 & & & & 0.089 \\
\hline No & 43 & 6 & 86.0 & & 44 & 2 & 95.5 & \\
\hline Yes & 47 & 14 & 70.2 & & 52 & 7 & 86.5 & \\
\hline Distant metastasis & & & & & & & & 0.003 \\
\hline No & & & & & 90 & 7 & 92.2 & \\
\hline Yes & & & & & 6 & 2 & 66.7 & \\
\hline Early-stage cancer & & & & 0.090 & & & & 0.009 \\
\hline Yes & 67 & 12 & 82.1 & & 67 & 3 & 95.5 & \\
\hline No & 23 & 8 & 65.2 & & 29 & 6 & 79.3 & \\
\hline
\end{tabular}

Data for histological differentiation, lymphovascular and perineural invasion could not be pathologically confirmed for all the patients. $V E G F$, vascular endothelial growth factor; LVI, lymphovascular invasion; PNI, perineural invasion; ER, estrogen receptor; PR, progesterone receptor; HER2, human epidermal growth factor receptor 2; HR+HER2-, hormone receptor-positive human epidermal growth factor receptor 2-negative breast cancer. 
A

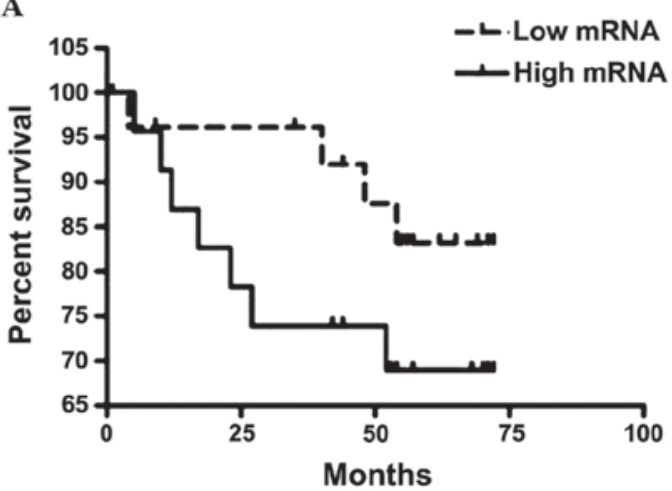

B

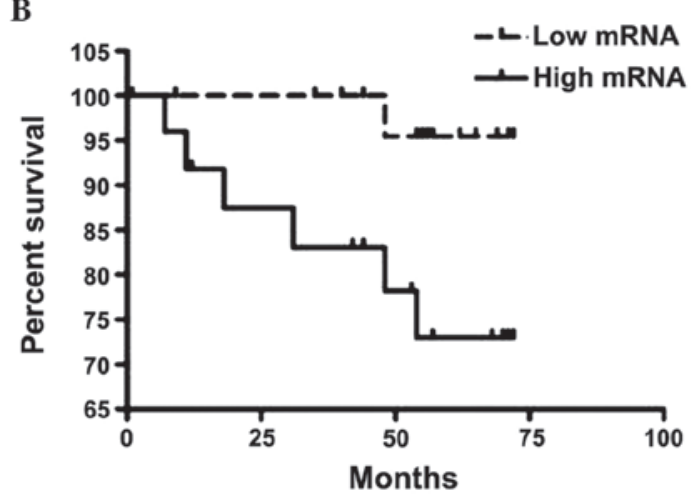

Figure 1. (A) Disease-free survival (DFS) and (B) overall survival (OS) by vascular endothelial growth factor (VEGF) expression among patients with hormone receptor-positive/human epidermal growth factor receptor 2 (HER2)-positive, HER2-positive and triple-negative breast cancer. High $V E G F$ expression was significantly associated with lower OS $(\mathrm{P}=0.03)$. However, the correlation between $V E G F$ expression and $\mathrm{DFS}$ was not significant $(\mathrm{P}=0.20)$.

regression analysis did not identify a significant correlation of clinicopathological characteristics with DFS and OS. The DFS and OS rates by VEGF expression in the hormone receptor-pos itive/HER2-positive, HER2-positive and triple-negative groups are shown in Fig. 1.

\section{Discussion}

The results of this study demonstrated an association between high VEGF expression and the presence of LVI. This finding was in concordance with those of several previous studies, as reviewed elsewhere (9). We also demonstrated a significant association of $V E G F$ expression with axillary nodal metastasis and lower OS in hormone receptor-positi ve/HER2-positive, HER2-positive and triple-negative breast cancer. However, due to the limited number of patients, the multivariate analysis failed to demonstrate a statistically significant difference.

Luminal B, HER2 and triple-negative subtypes were found to be more aggressive compared with luminal A subtype by tumor stage, lymph node status, or pathological type and also exhibited worse DFS and OS $(10,11)$. The identification of high-risk patients and selection of an intensive regimen may improve treatment outcome. The expression of VEGF was found to be associated with reduced response to adjuvant endocrine treatment. In a retrospective study of 699 breast cancer patients conducted by Linderholm et al (12), the patients who received adjuvant endocrine therapy and exhibited higher VEGF expression had significantly shorter relapse-free survival and OS. In a study of 160 ER-positive advanced breast cancer patients who received tamoxifen, an above median VEGF level was correlated with shorter progression-free survival and post-relapse OS (13). In a randomized control trial of 224 breast cancer patients comparing 2 years of tamoxifen treatment with no tamoxifen treatment, regardless of hormone receptor and HER2 status, the patients with ER-positive and VEGF-negative tumors significant benefited from tamoxifen after a 10-year follow-up, whereas the patients with ER- and VEGF-positive tumors did not benefit from tamoxifen treatment (14).

In a large study on 1,788 breast cancer patients, higher frequency of VEGF expression was correlated with luminal B,
HER2 and basal-like subtypes. VEGF expression was associated with increased risks of breast cancer-specific mortality and distant recurrence among luminal A patients (15). In the present study, however, we did not identify a significant difference in $V E G F$ expression frequency among breast cancer subtypes. In that study, conducted by Liu et al (15), VEGF immunohistochemistry was performed using VG1 antibody. VEGF positivity was defined as any positive staining in the cytoplasm of the tumor cells. By this definition, $72.5 \%$ of the patients were positive for VEGF. In our study, the median of the VEGF ratio was used as cut-off point. Using this definition, the patients were evenly distributed into low and high VEGF expression groups. The characteristics of the patients were also different, with higher stage and lower age at diagnosis compared with those reported earlier.

In conclusion, we demonstrated the role of $V E G F$ in non-luminal A (hormone receptor-positive/HER2-positive, HER2-positive and triple-negative) breast cancer. The assessment of the $V E G F$ status in this group of patients may help identify high-risk patients and may be used to guide appropriate treatment selection.

\section{References}

1. Jemal A, Bray F, Center MM, Ferlay J, Ward E and Forman D: Global cancer statistics. CA Cancer J Clin 61: 69-90, 2011.

2. National Cancer Institute: Information Technology Division. http://www.nci.go.th/th/cancer_record/cancer_rec1.html. Accessed November, 1, 2014.

3. Folkman J: What is the evidence that tumors are angiogenesis dependent? J Natl Cancer Inst 82: 4-6, 1990.

4. Folkman J: Tumor angiogenesis: Therapeutic implications. N Engl J Med 285: 1182-1186, 1971.

5. Burstein HJ, Chen YH, Parker LM, et al: VEGF as a marker for outcome among advanced breast cancer patients receiving anti-VEGF therapy with bevacizumab and vinorelbine chemotherapy. Clin Cancer Res 14: 7871-7877, 2008.

6. Miles DW, de Haas SL, Dirix LY, et al: Biomarker results from the AVADO phase 3 trial of first-line bevacizumab plus docetaxel for HER2-negative metastatic breast cancer. Br J Cancer 108: 1052-1060, 2013.

7. Schneider BP, Wang M, Radovich M, et al; ECOG 2100: Association of vascular endothelial growth factor and vascular endothelial growth factor receptor-2 genetic polymorphisms with outcome in a trial of paclitaxel compared with paclitaxel plus bevacizumab in advanced breast cancer: ECOG 2100. J Clin Oncol 26: 4672-4678, 2008. 
8. O-Charoenrat P, Rhys-Evans P, Modjtahedi $\mathrm{H}$ and Eccles SA: Vascular endothelial growth factor family members are differentially regulated by c-erbB signaling in head and neck squamous carcinoma cells. Clin Exp Metastasis 18: 155-161, 2000.

9. Sa-Nguanraksa D and O-Charoenrat P: The role of vascular endothelial growth factor a polymorphisms in breast cancer. Int J Mol Sci 13: 14845-14864, 2012.

10. Zheng S, Song QK, Ren Y, et al: The characteristics of breast cancer subtypes: Implications for treatment guidelines and individualized treatment strategies in China. Appl Immunohistochem Mol Morphol 22: 383-389, 2014.

11. Dawood S, Hu R, Homes MD, Collins LC, Schnitt SJ, Connolly J, Colditz GA and Tamimi RM: Defining breast cancer prognosis based on molecular phenotypes: Results from a large cohort study. Breast Cancer Res Treat 126: 185-192, 2011.

12. Linderholm B, Bergqvist J, Hellborg H, Johansson U, Linderholm M, von Schoultz E, Elmberger G, Skoog L and Bergh J: Shorter survival-times following adjuvant endocrine therapy in oestrogen- and progesterone-receptor positive breast cancer overexpressing HER 2 and/or with an increased expression of vascular endothelial growth factor. Med Oncol 26: 480-490, 2009.
13. Berns EM, Klijn JG, Look MP, et al: Combined vascular endothelial growth factor and TP53 status predicts poor response to tamoxifen therapy in estrogen receptor-positive advanced breast cancer. Clin Cancer Res 9: 1253-1258, 2003.

14. Rydén L, Stendahl M, Jonsson H, Emdin S, Bengtsson NO and Landberg G: Tumor-specific VEGF-A and VEGFR2 in postmenopausal breast cancer patients with long-term follow-up. Implication of a link between VEGF pathway and tamoxifen response. Breast Cancer Res Treat 89: 135-143, 2005.

15. Liu Y, Tamimi RM, Collins LC, Schnitt SJ, Gilmore HL, Connolly JL and Colditz GA: The association between vascular endothelial growth factor expression in invasive breast cancer and survival varies with intrinsic subtypes and use of adjuvant systemic therapy: Results from the Nurses' Health Study. Breast Cancer Res Treat 129: 175-184, 2011. 